\title{
Analisis Sistem Termal Pada Double Drum Water Tube Boiler Untuk Memproduksi Saturated Steam Pengaruh Rasio Udara Bahan Bakar
}

\author{
Agus Manggala ${ }^{1}$ Tahdid $^{2}$, Yendah Septi Anggriani*3 \\ ${ }^{1,2,3}$ Program Studi Teknik Energi/Teknik Kimia, \\ Politeknik Negeri Sriwijaya, Indonesia \\ Email: ${ }^{1}$ yenda.septi.anggriani@gmail.com
}

\begin{abstract}
Abstrak
Energi fosil seperti minyak bumi, gas alam, batubara dan lain-lain adalah energi yang saat ini sebagian besar digunakan untuk menghasilkan energi listrik dan umumnya menggunakan ketel uap (boiler) untuk mengkonversi energi tersebut. Oleh karena itu, peningkatan efisiensi ketel uap (boiler) akan mengurangi konsumsi energi dalam pembangkit maupun sektor industri lain. Pengupgradean dilakukan berdasarkan penelitian sebelumnya yaitu pada sistem injection boiler feed water, sistem control secondary udara pembakaran, serta sistem control air pada steam drum. Double Drum Water Tube Boiler digunakan untuk mengkonversikan air menjadi uap, dimana sumber panas untuk pemanasan berasal dari hasil pembakaran bahan bakar yang ada di ruang bakar. Double Drum Water Tube Boiler ini memiliki dua drum yang saling menyilang ke sumber panas dan tube dipasangkan berlawanan arah dengan drum. Bahan bakar yang digunakan pada penelitian ini yaitu bahan bakar cair solar. Tujuan keseluruhan dari penelitian ini agar proses dapat dilakukan secara steady state. Meteode penelitian yang digunakan untuk menghasilkan saturated steam. Variabel berubah yaitu rasio udara bahan bakar sedangkan variabel tetap yaitu air umpan dan jumlah bahan bakar. Dari hasil penelitian ini didapatkan titik optimal kinerja alat Double Drum Water Tube Boiler yaitu pada rasio udara bahan bakar 17.57, dimana effisiensi boiler yang didapatkan sebesar $65.62 \%$, dengan temperature steam yang dihasilkan sebesar $158,92{ }^{\circ} \mathrm{C}$, tekanan steam sudah mencapai tekanan optimum yaitu sebesar 5 bar serta rasio penguapan boiler sebesar 10,46.
\end{abstract}

Kata kunci: Double Drum Water Tube Boiler, Rasio Uara Bahan Bakar, Efisiensi Termal, Rasio Penguapan.

\section{Analysis Of Thermal Systems On Double Drum Water Tube Boilers To Produce Saturated Steam Based On The Influence Of Diesel Fuel Air Ratio}

\begin{abstract}
Fossil energy such as petroleum, natural gas, coal and others are energy that is currently mostly used to produce electrical energy and generally uses steam boilers to convert that energy. Therefore, increasing the efficiency of steam boilers will reduce energy consumption in plants and other industrial sectors. Double Drum Water Tube Boilerr used to convert water into steam, where the source of heat for heating comes from the combustion of fuel in the furnace. The upgrade was based on previous research on the injection boiler feed water system, the secondary control system of combustion air, and the water control system on the steam drum. Double Drum Water Tube Boiler is used to convert water into steam, where the heating source comes from the combustion of fuel in the combustion chamber. Double Drum Water Tube Boiler has two drums that cross each other to a heat source and the tube is paired in opposite directions with the drum. The fuel used in this research is diesel liquid fuel. The overall purpose of this research is so that the process can be done steady state. Research methods used to produce saturated steam. Variable change is the ratio of fuel air while the fixed variable is feed water and the amount of fuel. From the results of this study obtained the optimal point of performance of the Double Drum Water Tube Boiler tool is at the ratio of fuel air 17.57, where the efficiency of the boiler obtained by $65.62 \%$, with the resulting steam temperature of $158.92{ }^{\circ} \mathrm{C}$, steam pressure has reached the optimum pressure of 5 bar and boiler evaporation ratio of 10.46 .
\end{abstract}

Keywords: Double Drum Water Tube Boiler, Fuel Ratio, Efficiency Thermal, Evaporation Ratio.

\section{PENDAHULUAN}

Jurnal Energi fosil seperti minyak bumi, gas alam, batubara dan lain-lain adalah energi yang saat ini sebagian besar digunakan untuk menghasilkan energi listrik dan umumnya menggunakan ketel uap (boiler) 
untuk mengkonversi energi tersebut. Oleh karena itu, peningkatan efisiensi ketel uap (boiler) akan mengurangi konsumsi energi dalam pembangkit maupun sektor industri lain. Cadangan bahan bakar fosil semakin menipis namun permintaan terhadap minyak bumi, gas alam, dan batubara bumi diperkirakan akan meningkat hingga 47,5\%,91,6\%, dan 94,7\% masing masing sampai tahun 2030 [1].

Ketel Uap atau Boiler merupakan sejenis bejana tertutup yang mentransfer energi panas dari proses pembakaran ke air hingga menjadi uap panas (Steam). Uap panas tekanan tinggi kemudian digunakan untuk keperluan suatu proses yang paling dibutuhkan dari hampir semua sektor industri [2].

Uap panas (Steam) digunakan untuk menyediakan fasilitas pemanas di industri dan untuk penggerak turbin uap. Boiler juga digunakan pada laundry, dapur hingga sektor pariwisata [1]. boiler yang efisien juga memberikan pengaruh yang signifikan terhadap penghematan energi dan dibutuhkannya penelitian-penelitian untuk mendukung perkembangan teknologi boiler.

Penelitian sebelumnya telah dilakukan oleh Aisyah dkk [3] yang membahas Cross Section Water Tube Boiler. Dari hasil penelitian didapatkan nilai efisiensi termal boiler sebesar $61,12 \%$. Namun pada alat tersebut perlu dilakukan konstruksi lebih lanjut dimana pompa yang digunakan mengalami kerusakan karena tekanan balik pada Boiler. Maka dari itu pada penelitian ini kami memperbaiki sistem air umpan dengan menggunakan pompa kapasitas $40 \mathrm{~L} / m$ enit dengan tekanan 146 bar, pada sistem control level air dipasang sistem drain (pembuangan) agar air didalam akan tenang dan terbaca oleh alat watel level gauge saat proses berjalan.

Air terdiri dari molekul-molekul $\mathrm{H}_{2} \mathrm{O}$ yang bergerak bebas dalam lingkungannya. Molekul-molekul tidak akan meninggalkan lingkungannya karena ada gaya tarik menarik antar molekul itu sendiri yaitu karena adanya ikatan hidrogen. Apabila air tersebut dipanaskan maka kecepatan gerak molekulnya akan bertambah, namun molekul air itu belum mampu melapaskan diri dari lingkungannya. Bila air tersebut terus dipanaskan sampai temperatur didih air maka molekul-molekul air mampu melepaskan diri dari gaya tarik antar molekul. Peristiwa proses penguapan dari molekul-molekul tersebut disebut molekul uap dan uap yang terbentuk disebut uap kering [4].

Pembakaran merupakan suatu reaksi antara oksigen, bahan bakar dan sumber panas dengan reaksi : Bahan Bakar + Oksidan $\rightarrow$ Produk + Panas. Biasanya, bahan bakarnya mengandung karbon, seperti bensin, kayu, atau batu bara, dan oksidannya adalah oksigen di udara, meskipun ada bahan bakar non-karbon, terutama hidrogen. Namun, pembakaran dapat menyebabkan emisi karena adanya kandungan pengotor di udara, atau pembakaran tidak sempurna [5].

Rasio Udara-Bahan Bakar (AFR) adalah faktor kunci yang harus dikendalikan untuk mengoptimalkan proses pembakaran dalam hal efisiensi dan dampak lingkungan. AFR didefinisikan sebagai rasio antara laju aliran udara yang diinjeksikan $\left(\dot{\mathrm{m}}_{\mathrm{a}}\right)$ dan laju aliran bahan bakar yang diinjeksikan $\left(\dot{\mathrm{m}}_{\mathrm{f}}\right)$ :

$$
A F R=\frac{\dot{\mathrm{ma}}}{m f}
$$

AFR $\quad=$ Air fuel ratio (rasio udara bahan bakar)

$\dot{\mathrm{m}}_{\mathrm{a}} \quad$ = laju alir udara

$\dot{\mathrm{m}}_{\mathrm{f}} \quad=$ laju alir bahan bakar

Untuk proses pembakaran yang baik (suhu tinggi, lama waktu tinggal, dan pencampuran yang baik), ini juga cenderung mengurangi produksi $\mathrm{CO}$ dan karbon yang tidak terbakar ke tingkat yang dapat diterima. kondisi sub-stoikiometrik, pasti mengarah pada produksi CO dan sisa karbon yang tidak terbakar di dasar dan aliran abu terbang. Nilai lebih besar menyebabkan adanya kelebihan oksigen dalam gas buang. Oleh karena itu, kondisi lokal dalam tungku dapat berbeda dari keseimbangan udara-bahan bakar global dalam hal stoikiometri [6].

Bahan Bakar yang digunakan yaitu minyak solar yang merupakan minyak nabati hasil destilasi dari minyak bumi. Komponen solar didominasi oleh $\mathrm{C}_{16} \mathrm{H}_{34}$ [7].

Ada dua metode perhitungan efisiensi boiler yaitu metode langsung dan tidak langsung . Metode langsung yaitu dengan membandingkan energi yang terkandung pada steam terhadap energi bahan bakar boiler. Sedangkan metode tidak langsung adalah perbedaan antara kehilangan panas dan energi masuk.

Standar acuan untuk uji boiler yang adalah American Society of Mechanical Engineers PTC -4-1.Efisiensi dapat dihitung dengan persamaan :

$$
\text { Efisiensi }=\frac{\text { output }}{\text { input }} \text {. }
$$


Sedangkan rasio evaporasi boiler didefinisikan sebagai perbandingan massa steam untuk setiap massa bahan bakar [9].

$$
\text { evaporation ratio }=\frac{\text { quantity of steam }(\mathrm{kg})}{\text { quantity of fuel }(\mathrm{kg})}
$$

\section{METODE PENELITIAN}

\subsection{Pendekatan Desain Fungsional}

Rancang bangun upgrade Water Tube Boiler terdiri dari delapan unit utama yaitu steam drum, water drum, water tube, Furnace, superheater, pompa, kompresor, dan blower. Sistem tersebut dilengkapi dengan instrumen pendukung yaitu PI, TI, katup, katup pengaman, water level gauge dan katup drain.

\subsection{Pendekatan Desain Stuktural}

Gambar Teknik Rancang Bangun Water Tube Boiler dapat dilihat pada gambar berikut :

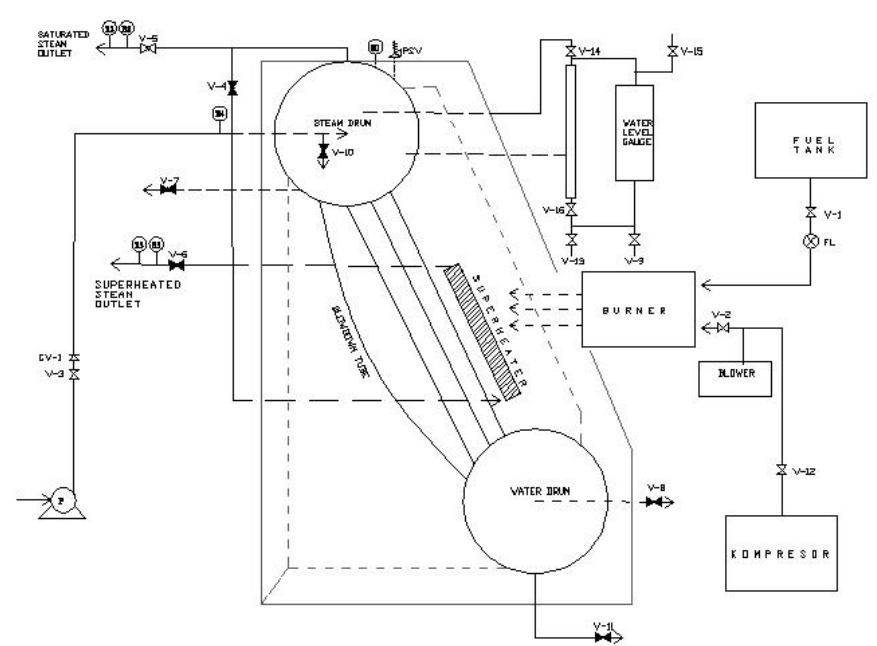

Gambar 1. Rancang Bangun Water Tube Boiler

\subsection{Perlakuan dan Rancangan Percobaan}

Pada penelitian water tube boiler ditetapkan variabel tetap yaitu air umpan dan bahan bakar. kemudian variabel berubah berupa rasio udara bahan bakar solar yaitu pada 15.78, 16.38, 16.97, 17.57, dan 18.16 dengan udara excess sebesar $6 \%, 10 \%, 14 \%, 18 \%$, dan $22 \%$.

Proses pembuatan rancang bangun beserta penelitian akan dilakukan di Laboratorium Program Studi Teknik Energi Jurusan Teknik Kimia Politeknik Negeri Sriwijaya Palembang.

\subsection{Prosedur Penelitian}

Tahapan prosedur penelitian yaitu persiapan hingga pengoperasian. Standar pengoperasian berdaasarkan metode pasa ASME PD 769 Sectin VI. Tahapan pertama yaitu commisioning boiler serta persiapan pengoperasian untuk menguji kebocoran, kesiapan peralatan, pengujian safety valve serta distribusi saluran bahan bakar solar. Kemudian pengoperasian boiler dengan tahapan yaitu :

1. Memastikan boiler sudah siap untuk dioperasikan

2. Menyiapkan bahan bakar solar dan set kompresor

3. Melakukan pengaturan-pengaturan operasi perbedaan rasio udara bahan bakar solar dengan setting sesuai yang dikehendaki, sehingga operasi dapat berlangsung dengan effisiensi yang maksimum.

4. Setelah proses pengisian feed water, ventisai udara dan pembakaran boiler siap dioperasikan dalam keadaan non steady state

5. Setelah tekanan mencapai 10 bar proses non steady state selesai dan masuk ke keadaan steady state proses continue 
6. Pada pengoperasian steady state untuk mengambil data saturated steam valve (V-05) dibuka secara perlahan sampai menghasilkan steam sebanyak $5 \mathrm{~L} / \mathrm{jam}$, selanjutnya valve ( V-03) dan (V-10) dibuka untuk menyuplai air. Air yang disuplaiakan sesuai dengan jumlah steam yang di keluarkan dilihat dari level volume (LV-01)

7. Jika kondisi pengoperasian telah stabil maka lakukan pencatatan terhadap data-data yang diperlukan seperti tekanan (PI-02)dan temperature (TI-01) pada beberapa unit peralatan lainnya pada matrik yang telah di tentukan

8. Mengulang percobaan dengan rasio udara bahan bakar yang berbeda, sesuai dengan rasio udara bahan bakar yang telahditentukan

9. Setelah itu mematikan proses unit steam power sesaui dengan SOP.

10.Lakukan analisa hasil percobaan dan lakukan perhitungan laju produksi yang didapatkan.

11. Untuk menghentikan proses pengoperasian yang pertama dilakukan menutup suplay bahan bakar menutup valve (V-02) pada kompressor. Membuka valve pada satureated steam (V-05) sampai kondisi ruang.

12. Setelah boiler dalam kondisi normal dibuka valve (V-07) dan (V-08) untuk mengeluarkan air dalam boiling drum. Jika air pada boiler telah dikeluarkan tutup kembali seluruh valve, Sehingga boiler siap dioperasikan kembali.

\section{HASIL DAN PEMBAHASAN}

Pada Pada penelitian ini dilakukan analisis sistem termal double drum water tube boiler yaitu bagaimana pengaruh rasio udara bahan bakar terhadap kinerja boiler dalam memproduksi saturated steam dengan menggunakan bahan bakar solar.

\subsection{Efisiensi Termal Boiler}

Efisiensi termal menunjukkan kinerja boiler. Semakin tinggi efisiensi semakin baik kinerja boiler[10]. Berikut grafik hubungan rasio udara bahan bakar terhadap efisiensi boiler:



Gambar 2. Grafik hubungan rasio udara bahan bakar dan Efisiensi Termal.

Efisiensi termal boiler mengalami kenaikan seiring dengan kenaikan rasio udara bahan bakar. Titik optimal yaitu pada rasio udara 17,57 dimana pada kondisi tersebut tekanan steam yang diinginkan sudah tercapai. Semakin tinggi rasio udara bahan bakar semakin tinggi pula tekanan steam yang dihasilkan. Tekanan steam mengalami kenaikan secara signifikan pada penambahan jumlah udara hingga rasio udara / bahan bakar 17,57, hal ini terjadi karena penambahan tersebut mengakibatkan kenaikan jumlah panas yang diterima steam sehingga meningkatkan jumlah kalor yang terserap sehingga tekanan steam menjadi meningkat. Namun, pada rasio 18,16 , kenaikan tekanan steam tidak terlalu signifikan. Hal ini dikarenakan temperatur saturated steam yang dihasilkan hanya naik $1^{\circ} \mathrm{C}$ dari rasio udara bahan bakar 17,57 sehingga kenaikan kalor yang termanfaatkan hanya sedikit dan menyebabkan kenaikan tekanan steam nya kecil.

Pada percobaan yang dilakukan tekanan steam yang ingin dicapai yaitu 5 bar, dikatakan rasio ke-4 yang paling optimal karena rasio yang digunakan lebih kecil di bandingkan pada rasio ke-5 dengan tekanan yang telah mencapai target yang diinginkan. Semakin tinggi nilai entalpi semakin besar jumlah energi panas yang dimiliki steam. Sehingga nilai optimal yaitu pada rasio udara 17,57 dimana nilai entalpi sebesar $2756,2 \mathrm{~kJ} / \mathrm{kg}$ dikarenakan pada rasio udara 18,16 membutuhkan udara yang lebih banyak namun nilai entalpi hanya mengalami kenaikan kecil. Jumlah udara yang lebih besar mengakibatkan suhu cerobong yang tinggi menyebabkan panas terbuang sehingga panas yang termanfaatkan menjadi kecil. Entalpi didefinisikan yaitu 
jumlah energi yang terkandung dalam suatu sistem pada keadaan tekanan konstan atau jumlah energi panas yang dimiliki oleh uap air (steam) pada tiap kg nya[11]

Semakin tinggi nilai efisiensi termal maka kehilangan panas semakin kecil. diketahui bahwa kehilangan panas menurun seiring dengan meningkatnya rasio udara bahan bakar. Kehilangan panas terbesar dari kehilangan energi dalam boiler terjadi di stack gas. Suhu dan volume gas cerobong yang meninggalkan boiler adalah faktor utama untuk penilaian kehilangan panas [1]. Excess air serta rasio udara bahan bakar yang optimum akan meminimalisir jumlah udara yang keluar cerobong sehingga kecepatan gas keluar cerobong berkurang dan mengakibatkan suhu gas buang menurun sehingga dapat mengurangi heat loss [1].

\subsection{Rasio Penguapan Termal Boiler}

Sedangkan rasio penguapan (evaporasi) boiler didefinisikan jumlah kilogram steam yang diproduksi untuk setiap kilogram bahan bakar. Rasio tersebut menunjukan kemampuan kemampuan Water Tube Boiler dalam memanfaatkan panas dari bahan bakar untuk menghasilkan uap (steam) serta untuk mengetahui kualitas bahan bakar yang digunakan [12].

Berikut merupakan grafik rasio penguapan boiler untuk tiap rasio udara bahan bakar :

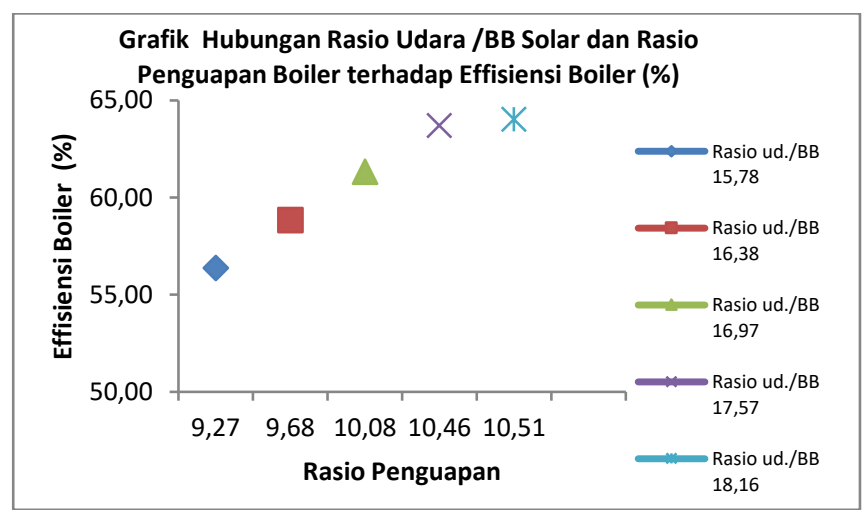

Gambar 3. Grafik hubungan rasio udara bahan bakar dan Rasio Penguapan.

Dari grafik dapat dilihat semakin tinggi rasio udara bahan bakar (air fuel ratio) maka efisiensi dan rasio penguapan nya semakin besar. Diketahui rata- rata rasio penguapan water tube boiler sebesar 10 serta rasio penguapan dititik optimal yaitu sebesar 10,46 yaitu pada rasio udara bahan bakar 17,57 karena pada kondisi tersebut tekanan steam yang diinginkan sudah tercapai.

\section{KESIMPULAN}

Effisiensi pada cross double drum water tube boiler optimal pada rasio udara/BB ke-4 yaitu 17.57 dengan effisiensi $63,72 \%$, heat loss 36,28\%, udara excess $18 \%$, tekanan 5 Bar, entalpi $2756,2 \mathrm{~kJ} / \mathrm{kg}$ dan temperatur $158,92^{\circ} \mathrm{C}$ serta rasio penguapan boiler sebesar 10,51 . Kenaikan jumlah panas yang diterima steam meningkatkan jumlah kalor yang terserap sehingga tekanan steam menjadi meningkat. Tekanan yang tinggi membuat nilai entalpi meningkat dimana entalpi merupakan energi panas yang dimiliki oleh uap air sehingga nilai efisiensi meningkat. Semakin tinggi nilai efisiensi semakin besar rasio penguapan artinya semakin besar jumlah kilogram steam yang diproduksi untuk setiap kilogram bahan bakar.

\section{DAFTAR PUSTAKA}

[1] M. C. Barma, R. Saidur, S. M. A. Rahman, A. Allouhi, B. A. Akash, and S. M. Sait, "A review on boilers energy use, energy savings, and emissions reductions," Renew. Sustain. Energy Rev., vol. 79, pp. 970-983, 2017.

[2] S. S. H. M., "Industrial Boiler Operation,” https://jrte.org/wp-content/uploads/2020/07/Industrial-BoilerOperation.pdf. (accessed Jun 22, 2021).

[3] A. S. Ningsih, A. Syakdani, I. Rusnadi, Y. Oktaviani, F. Veronica, and J. T. Anisya, "Efisiensi termal produksi steam ditinjau Dari rasio Udara bahan Bakar solar Pada Cross Section water tube boiler," KINERJA TEKNIK KIMIA, vol. 12, no. 1, pp. 18-22, 2021.

[4] K. E. Heselton, Boiler Operator's Handbook. River Publishers, 2020

[5] P. L. Russell, G. W. Beal, R. A. Sederquist, and D. Schultz, "Evaluation of concepts for controlling 
exhaust emissions from minimally processed petroleum and synthetic fuels," in Volume 2: Coal, Biomass and Alternative Fuels; Combustion and Fuels; Oil and Gas Applications; Cycle Innovations, 1981.

[6] J. Blondeau et al., "Burner air-fuel ratio monitoring in large pulverised-fuel boilers using advanced sensors: Case study of a 660 MW e coal-fired power plant," Therm. Sci. Eng. Prog., vol. 5, pp. 471-481, 2018.

[7] Pertamina.com. http://www.pertamina.com/indonesia/head-office/hilirppdn/product/prdsolar.html. (accessed Jun 22, 2021].

[8] C. V. Moore, “ASME Boiler and Pressure Vessel Code Short Courses," J. Press. Vessel Technol., vol. 97, no. 2, pp. 123, 1975.

[9] M. K. Bora and S. Nakkeeran, "Performance analysis from the efficiency estimation of coal fired boiler," Psu.edu.http://citeseerx.ist.psu.edu/viewdoc/download?doi=10.1.1.1080.1289\&rep=rep1\&type= pdf. (accessed Jun 23, 2021).

[10] United Nations Environment Program, Energy efficiency guide for industry in Asia. New York, NY: United Nations, 2006.

[11] G. S. Callendar and A. Egerton, "An experimental study of the enthalpy of steam," Philos. trans. R. Soc. Lond., vol. 252, no. 1006, pp. 133-164, 1960.

[12] M. F. Putra, D. S. Wijayanto, and N. A. Pambudi, "ANALISIS PERFORMA BOILER BASUKI BERDASARKAN RASIO ANTARA BAHAN BAKAR DAN STEAM DI PT. INDO ACIDATAMA Tbk," NOZEL Jurnal Pendidikan Teknik Mesin, vol. 1, no. 2, p. 80, 2019 